\title{
Valor nutricional de híbridos de sorgo para corte e pastejo (Sorghum bicolor x Sorghum sudanense) em diferentes fases fenológicas
}

\section{Nutritional value of sorghum-sudangrass hybrids (Sorghum bicolor $\mathrm{x}$ Sorghum sudanense) harvested at different stages of maturity}

\author{
Pedro Dias Sales Ferreira ${ }^{1 *}$; Lúcio Carlos Gonçalves²; \\ José Avelino Santos Rodrigues ${ }^{3}$; Diogo Gonzaga Jayme²; \\ Eloísa de Oliveira Simões Saliba'; ${ }^{2}$ Otaviano de Souza Pires Neto ${ }^{1}$; \\ Diego Soares Gonçalves Cruz'; Felipe Antunes Magalhães"; \\ Gabriel de Oliveira Ribeiro Junior ${ }^{5}$; Frederico Osório Velasco ${ }^{6}$
}

\section{Resumo}

\begin{abstract}
Objetivou-se avaliar o valor nutricional de quatro híbridos de sorgo em quatro idades de corte. Os híbridos BR800, BRS810 (bmr), BRS802 e 156x2784 foram colhidos e avaliados nas idades de 52, 61, 67 e 74 dias após o plantio. O BRS810 ( $(\mathrm{mr})$ e o BRS802 são pares isogênicos que se diferenciam apenas pela presença da mutação $b m r-6$ no primeiro. Determinou-se os teores de matéria seca (MS), proteína bruta (PB), fibra em detergente neutro (FDN), fibra em detergente ácido (FDA) e lignina (LIG) e as digestibilidades in vitro da MS (DIVMS) e da FDN (DIVFDN). A interação entre híbrido e idade de corte foi significativa para os parâmetros FDN, FDA, DIVMS e DIVFDN. Observou-se aumento linear do teor de MS com o aumento da idade de corte. $O$ teor de $\mathrm{PB}$ apresentou efeito quadrático com ponto de máximo em 55,8 dias. Independente da idade de corte, o híbrido BR800 apresentou o maior teor de PB (12,5\%) e os híbridos BRS802 e 156x2784 os menores teores (9,7 e 10,3\%, respectivamente). Os híbridos BR800, BRS810 ( $b m r)$ e BRS802 apresentaram efeito quadrático para o teor de FDN com pontos de máximo aos 62,0;61,7 e 60,4 dias, respectivamente. Nas idades de 52 e 67 dias o híbrido BRS810 ( bmr ) apresentou teor de FDN inferior aos demais híbridos (64,2 e 66,4\%, respectivamente). Em relação aos teores de FDA os híbridos que compõem o par isogênico apresentaram efeito linear decrescente e, nas idades de 52,61 e 67 dias, o híbrido mutante apresentou menor teor de FDA em relação ao seu par isogênico. Não houve efeito linear ou quadrático sobre o teor de LIG. Independente da idade de corte, os híbridos BRS802 e 156x2784 apresentaram maior teor de LIG $(4,42$ e $4,16 \%$, respectivamente), o BR800 valor intermediário (3,69\%) e o BRS810 ( $b m r)$ o menor valor $(2,49 \%)$. O híbrido BRS810 (bmr) apresentou DIVMS e DIVFDN superior ao seu par isogênico em todas as idades avaliadas. A mutação $b m r-6$ provocou melhora do valor nutritivo em função da redução dos teores de FDN, FDA e LIG e aumento do teor de PB e da DIVMS e DIVFDN. O híbrido BR800 destacou-se em relação aos demais híbridos normais por apresentar menores teores de FDA e LIG e maior DIVFDN.

Palavras-chave: Capim-sudão, digestibilidade in vitro da MS e da FDN, mutação $b m r$, nervura marrom
\end{abstract}

\footnotetext{
${ }^{1}$ Discentes do curso de Doutorado em Zootecnia da Escola de Veterinária da Universidade Federal de Minas Gerais, UFMG, Belo Horizonte, MG. E-mail: ferreira.pds@gmail.com; otaviano.pires@yahoo.com.br; diegosoaresvet@hotmail.com

2 Profs., Dept ${ }^{\mathrm{o}}$ de Zootecnia da Escola de Veterinária da Universidade Federal de Minas Gerais, UFMG, Belo Horizonte, MG. E-mail: luciocg@vet.ufmg.br; dgjayme@gmail.com, saliba@ufmg.br

3 Pesquisador da Embrapa Milho e Sorgo, Sete Lagoas, MG. E-mail: avelino.rodrigues@embrapa.br

${ }^{4}$ Prof., Faculdade de Medicina Veterinária da Universidade Federal de Uberlândia, UFU, Uberlândia, MG. E-mail: felipeam.vet@ gmail.com

5 Pesquisador Visitante, bolsista do Ciência Sem Fronteiras no Lethbridge Research Centre, Agriculture and Agri-Food Canada, Lethbridge, AB, Canadá. E-mail: gabrielorjunior@yahoo.com.br

${ }^{6}$ Dr. em Zootecnia, UFMG, Belo Horizonte, MG. E-mail: fredericovelasco@gmail.com

* Autor para correspondência
} 


\begin{abstract}
The aim of this work was to evaluate the nutritional value of four sorghum-sudangrass hybrids harvested at four different stages of maturity. The hybrids evaluated were BR800, BRS810 (bmr), BRS802 and 156x2784. Hybrids were harvested at 52, 61, 67 and 74 days after seeding. BRS802 and BRS 810 $(\mathrm{bmr})$ are sorghum-sudangrass hybrids isogenic pairs that are distinguished only by the presence of $b m r-6$ mutation on BRS810. Samples were analyzed for dry matter (DM), crude protein (CP), neutral detergent fiber (NDF), acid detergent fiber (ADF) and acid detergent lignin (ADL) content and in vitro DM and NDF digestibility (IVDMD and IVNDFD). Interaction between hybrid and stage of maturity was observed for NDF, ADF, IVDMD and IVNDFD. A linear increase in DM content was observed with increasing stage of maturity. A quadratic effect was observed for $\mathrm{CP}$ content with increasing stage of maturity, and the maximum CP value was estimated to be with 55.8 days. The hybrid BR 800 had the highest CP content (12.5\%) and the hybrids BRS 802 and 156x2784 the lowest CP content (9.7 and $10.3 \%$, respectively) for all stages of maturity evaluated. A quadratic effect in NDF content was observed with increasing stage of maturity for the hybrids BR800, BRS810 $(\mathrm{bmr})$ and BRS802 with the maximum values estimated to be with $62.0,61.7$ and 60.4 days after seeding respectively. With 52 and 67 days after seeding the hybrid BRS810 ( $b m r)$ had the lowest NDF content ( 64.2 and $66.4 \%$, respectively). The isogenic pair, hybrids BRS802 and BRS810 (bmr), had a linear decrease in ADF content with increasing stage of maturity, and with 52,61 and 67 days after seeding the bmr hybrid had lower ADF content compared to its counter pair (BRS802). No linear or quadratic effect with increasing stage of maturity was observed for ADL content. The hybrids BRS802 and 156x2784 had the highest ADL content (4.42 and 4.16\%, respectively) regardless of the stage of maturity. BRS810 (bmr) had the lowest ADL content (2.49\%) and intermediate value was observed for BR800 (3.69\%). The hybrid BRS810 (bmr) had higher IVDMD and IVNDFD than its isogenic pair (BRS802) for all stages of maturity evaluated. The $b m r-6$ mutation increased the nutritional value of the sorghum-sudangrass hybrid through reduction in the NDF, ADF and ADL content and increases in CP, IVDMD and IVNDFD. Comparing the normal hybrids (non $b m r$ ), the hybrid BR800 stood out because of its lower ADF and ADL content and higher IVNDFD.
\end{abstract}

Key words: $B m r$ mutation, brown midrib, in vitro DM and NDF digestibility, sudangrass

\section{Introdução}

Os híbridos de sorgo obtidos no cruzamento entre Sorghum bicolor (L.) Moench e Sorghum sudanense (Piper) Stapf, também designados como sorgo de corte e pastejo, são considerados uma alternativa para manter a estabilidade da produção de forragem e, consequentemente, de leite e de carne ao longo do ano. Embora existam poucos cultivares comercialmente disponíveis no Brasil, os híbridos de sorgo com capim-sudão têm sido bem aceitos pelos pecuaristas e constituem um recurso disponível para alongar o período de utilização de forragem fresca com alto valor nutricional.

O conhecimento do valor nutricional de forrageiras não só permite o balanceamento adequado das dietas como também fornece subsídios para adoção de estratégias de manejo e para a seleção de cultivares, visando à melhoria de sua qualidade nutricional. Plantas mutantes $b m r$ (do inglês brown midrib, ou nervura central marrom) são caracterizadas por apresentar redução no conteúdo e alterações na composição da lignina, levando a uma maior digestibilidade da parede celular e, consequentemente, podem proporcionar maiores consumos e desempenho animal (OBA; ALLEN, 2000; BECK et al., 2007; LEDGERWOOD et al., 2009; ASTIGARRAGA et al., 2014). O programa de melhoramento genético de plantas forrageiras desenvolvido pela Embrapa Milho e Sorgo tem selecionado novos híbridos de sorgo com capimsudão, incluindo genótipos portadores da mutação $b m r$, que devem ser avaliados para utilização na alimentação de ruminantes.

Apesar dos trabalhos publicados por Ademosum, Baumgardt e Scholl (1968) e Worker Junior (1973) 
mostrarem queda do valor nutricional com o avanço do estádio de maturação de híbridos de sorgo com capim-sudão e essa ser a resposta mais frequente observada em gramíneas tropicais, poucos são os trabalhos que avaliaram o valor nutricional do sorgo de corte e pastejo em diferentes idades de corte, sendo, portanto, necessário entender como ocorrem as mudanças na composição química dessa forrageira ao longo do tempo.

Objetivou-se avaliar o valor nutricional de quatro híbridos de sorgo para corte e pastejo submetidos ao corte em quatro idades após o plantio.

\section{Material e Métodos}

Os híbridos de sorgo com capim-sudão BR 800, BRS 810 (bmr), BRS 802 e 156x2784 foram cultivados nas dependências da Embrapa Milho e Sorgo, localizada no $\mathrm{km} 65$ da rodovia MG 424, no município de Sete Lagoas - MG, entre as coordenadas $19^{\circ} 28^{\prime}$ de latitude sul e $44^{\circ}$ 15 ' de longitude oeste de Greenwich. A região apresenta altitude média de $732 \mathrm{~m}$, precipitação pluviométrica anual média de $1340 \mathrm{~mm}$ com concentração de $86 \%$ entre os meses de novembro e abril e clima do tipo AW (clima de savana, com inverno seco e temperatura média acima de $18{ }^{\circ} \mathrm{C}$ no mês mais frio), segundo a classificação de Köppen. Os dados climáticos fornecidos pelo Núcleo de Tecnologia da Informação da Embrapa Milho e Sorgo, referentes aos meses em que o experimento foi realizado, encontram-se na Tabela 1. Os híbridos BRS 810 (bmr) e BRS 802 são pares isogênicos que se diferenciam apenas pela presença do locus bmr-6 no primeiro, conferindo a este o fenótipo de nervura marrom (brown midrib ou bmr). O híbrido 156x2784 é um material experimental e pertence ao programa de melhoramento genético do Centro Nacional de Pesquisa do Milho e Sorgo da Embrapa e os híbridos BR 800, BRS 810 (bmr) e BRS 802 são híbridos comerciais da mesma instituição. O plantio foi realizado em 30 de janeiro de $2010 \mathrm{em}$ quatro canteiros experimentais para cada um dos quatro híbridos em cada idade de corte (totalizando 64 canteiros). Os canteiros continham oito linhas de cinco metros de comprimento e espaçamento entre linhas de 0,35 metros. Realizou-se adubação no plantio e de cobertura de acordo com a análise do solo e as necessidades da cultura, sendo utilizados $400 \mathrm{~kg} /$ ha da fórmula 08-28-16 (N:P:K) + Zinco $(0,5 \mathrm{~kg} / \mathrm{ha})$ no plantio e $100 \mathrm{~kg} / \mathrm{ha}$ de ureia em cobertura, 25 dias após o plantio.

Tabela 1. Dados climáticos mensais da área onde foi realizado o experimento.

\begin{tabular}{lcccccc}
\hline \multicolumn{7}{c}{ Temperatura $\left({ }^{\circ} \mathrm{C}\right)$} \\
Mês & Máxima & Mínima & Média & $\begin{array}{c}\text { Precipitação } \\
(\mathrm{mm})\end{array}$ & $\begin{array}{c}\text { Umidade Relativa } \\
(\%)\end{array}$ & $\begin{array}{c}\text { Insolação } \\
(\mathrm{h} / \text { dia })\end{array}$ \\
\hline Janeiro & 29,9 & 19,4 & 23,6 & 327,7 & 75,2 & 6,6 \\
Fevereiro & 30,0 & 19,3 & 23,7 & 208,6 & 75,0 & 7,3 \\
Março & 30,8 & 19,0 & 23,8 & 174,1 & 75,4 & 7,2 \\
Abril & 28,6 & 17,2 & 21,6 & 67,7 & 75,1 & 7,1 \\
\hline
\end{tabular}

Fonte: Elaboração dos autores.

Os cortes foram realizados aos 52, 61, 67 e 74 dias após o plantio, a uma altura de cinco centímetros do solo e somente nas quatro linhas centrais de cada canteiro. Dez plantas de cada canteiro foram picadas em partículas de aproximadamente dois centímetros e pré-secadas em estufa de ventilação forçada a $55^{\circ} \mathrm{C}$ por 72 horas. Após a pré-secagem o material foi pesado e processado em moinho tipo Willey 
com peneira de um milímetro e armazenado em recipientes de polietileno devidamente identificados e lacrados.

No Laboratório de Nutrição Animal da Escola de Veterinária da UFMG, em Belo Horizonte, foram realizadas as análises de matéria seca (MS) em estufa a $105^{\circ} \mathrm{C}$, proteína bruta (PB) pelo método de Kjeldahl (AOAC, 1995) e frações fibrosas (fibra em detergente neutro (FDN) e fibra em detergente ácido (FDA)) pelo método sequencial de Robertson e Van Soest (1981) em aparelho analisador de fibra modelo Ankom 220 (Ankom Technology, Macedon, NY, EUA). O teor de lignina foi determinado no resíduo das análises de FDA em solução de ácido sulfúrico (ROBERTSON; VAN SOEST, 1981). Determinou-se a digestibilidade in vitro da matéria seca (DIVMS) segundo procedimento descrito por Tilley e Terry (1963) e adaptado por Holden (1999) para utilização do simulador de rúmen Daisy ${ }^{I I}$ (Ankom Technology, Macedon, NY, EUA). Foram determinados os teores de FDN no resíduo do procedimento de DIVMS, a fim de determinar-se a digestibilidade in vitro da FDN (DIVFDN).

Utilizou-se o delineamento experimental de blocos ao acaso em arranjo fatorial com quatro híbridos, quatro idades de corte e quatro canteiros (blocos). As variáveis foram submetidas à análise de variância por meio do software SISVAR (versão 5.0). A comparação entre híbridos em cada idade de corte foi realizada utilizando-se o teste de StudentNewman-Keuls (SNK) com nível de significância igual a 5\%. Para a avaliação dos híbridos ao longo das idades de corte foi realizada análise de regressão, sendo que foram testadas equações lineares e quadráticas e apresentada a que melhor se ajustou aos dados, de acordo com seu nível de significância, significado biológico e valor do coeficiente de determinação $\left(\mathrm{R}^{2}\right)$. Também foi realizada análise de correlação entre as variáveis pelo método de Pearson.

\section{Resultados e Discussão}

Não houve interação entre híbrido e idade de corte para o teor de MS (Tabela 2) $(\mathrm{P}>0,05)$ e não foram observadas diferenças entre híbridos $(\mathrm{P}>0,05)$, que apresentaram efeito linear crescente com aumento médio diário de $0,44 \%$ no teor de MS a cada dia de avanço no ciclo da cultura. Os valores obtidos nesse experimento se aproximam dos resultados descritos por Neumann et al. (2010) ao avaliarem quatro híbridos de sorgo com capimsudão, que observaram teor de $\mathrm{MS}$ da planta inteira variando de 10,2 a $13,1 \%$ quando o corte foi realizado 40 dias após o plantio e de 16,9 a $21,7 \%$ quando o corte foi realizado 110 dias após o plantio, com aumento linear ao longo do tempo. Os teores de MS observados nesse experimento estão abaixo do mínimo recomendado por McDonald, Henderson e Heron (1991) para ensilagem de forrageiras, embora Jayme et al. (2007) tenham obtido bons padrões de fermentação ao ensilar 6 híbridos de sorgo com capim-sudão colhidos 60 dias após o plantio e contendo 16,6\% de MS em média. Além disso, de acordo com o NRC (1989), ocorre uma diminuição na ingestão de $\mathrm{MS}$ em $0,02 \%$ do peso vivo para cada aumento de $1 \%$ na umidade da dieta, a partir de 50\%. Portanto, em função do alto teor de umidade apresentado pelos híbridos, especialmente nas primeiras idades de corte, é possível que o consumo deste alimento seja deprimido, embora Ribas (2010) tenha obtido altos consumos voluntários de MS $\left(94,8 \mathrm{~g} / \mathrm{kg}^{0,75} / \mathrm{dia}\right.$, em média) por ovinos alimentados com um híbrido de sorgo com capim-sudão colhido 64 dias após o plantio e contendo $16,6 \%$ de MS em média. 
Tabela 2. Teor de matéria seca (MS) em porcentagem da matéria natural, coeficiente de variação (CV) e equações de regressão com seus respectivos coeficientes de determinação $\left(\mathrm{R}^{2}\right)$ e nível de significância $(\mathrm{P})$ de quatro híbridos de sorgo com capim-sudão em quatro idades de corte.

\begin{tabular}{ccccccc}
\hline \multicolumn{7}{c}{ Idade ao Corte (dias) } \\
\hline Híbrido & 52 & 61 & 67 & 74 & Média & Equação de Regressão \\
\hline BR 800 & 8,14 & 12,23 & 15,30 & 18,80 & $13,62^{\mathrm{A}}$ & \\
BRS 810 $(\mathrm{bmr})$ & 8,65 & 13,14 & 13,88 & 16,55 & $12,56^{\mathrm{A}}$ & $\mathrm{Y}=-14,752+0,441 \mathrm{D}$ \\
BRS 802 & 8,95 & 13,14 & 14,41 & 18,09 & $13,65^{\mathrm{A}}$ & $\left(\mathrm{R}^{2}: 99,4 ; \mathrm{P}<0,01\right)$ \\
$156 \times 2784$ & 8,03 & 12,17 & 13,66 & 17,64 & $12,88^{\mathrm{A}}$ & \\
\hline
\end{tabular}

Médias seguidas por letras distintas nas colunas diferem pelo teste $\mathrm{SNK}(\mathrm{P}<0,05), \mathrm{CV}=9,63 \%$.

$\mathrm{D}=$ dias após o plantio, variando de 52 a 74 dias.

Fonte: Elaboração dos autores.

Não houve interação entre híbrido e idade de corte para o teor de proteína bruta $(\mathrm{PB})(\mathrm{P}>0,05)$ (Tabela 3), sendo que foram observados efeitos quadráticos com pontos de máximo em 55,8 dias após o plantio. O híbrido BR 800 destacou-se por apresentar valores superiores aos demais $(\mathrm{P}<0,05)$ e o híbrido BRS 810 (bmr) apresentou valores superiores aos híbridos BRS 802 e 156x2784 $(\mathrm{P}<0,05)$, que não diferiram entre si $(\mathrm{P}>0,05)$, independente da idade de corte. Em todos os cortes realizados os híbridos avaliados apresentaram teores de PB superiores aos classificados como críticos para um funcionamento adequado do rúmen.

Tabela 3. Teor de proteína bruta (PB) em porcentagem da MS, coeficiente de variação $(\mathrm{CV})$ e equações de regressão com seus respectivos coeficientes de determinação $\left(\mathrm{R}^{2}\right)$ e nível de significância $(\mathrm{P})$ de quatro híbridos de sorgo com capim-sudão em quatro idades de corte.

\begin{tabular}{crrrrrc}
\hline \multicolumn{7}{c}{ Idade ao Corte (dias) } \\
\hline Híbrido & \multicolumn{1}{c}{52} & \multicolumn{1}{c}{61} & \multicolumn{1}{c}{67} & \multicolumn{1}{c}{74} & Média & Equação de Regressão \\
\hline BR 800 & 14,16 & 13,48 & 12,13 & 10,08 & $12,46^{\mathrm{A}}$ & \\
BRS 810 (bmr) & 12,04 & 12,13 & 11,79 & 10,80 & $11,69^{\mathrm{B}}$ & $\mathrm{Y}=-13,772+0,893 \mathrm{D}-0,008 \mathrm{D}^{2}$ \\
BRS 802 & 9,81 & 10,09 & 10,10 & 8,67 & $9,67^{\mathrm{C}}$ & $\left(\mathrm{R}^{2}: 98,8 ; \mathrm{P}<0,01\right)$ \\
$156 \times 2784$ & 10,54 & 10,76 & 10,92 & 8,99 & $10,30^{\mathrm{C}}$ & \\
\hline
\end{tabular}

Médias seguidas por letras distintas nas colunas diferem pelo teste $\mathrm{SNK}(\mathrm{P}<0,05), \mathrm{CV}=8,73 \%$.

$\mathrm{D}=$ dias após o plantio, variando de 52 a 74 dias.

Fonte: Elaboração dos autores.

Ademosum, Baumgardt e Scholl (1968), avaliando um híbrido de sorgo de corte e pastejo em 12 idades de corte (variando de 52 a 85 dias após o plantio) observaram que o teor de $\mathrm{PB}$ diminuiu ao longo dos cortes, variando de 19,6 a 10,3\%. Já Beck et al. (2007) observaram valores de PB iguais a 12,6; 9,7; 6,9; 5,0 e 4,3\% quando um híbrido de sorgo com capim-sudão foi submetido ao corte $34,41,48,55$ e 63 dias após o plantio, respectivamente, embora esses autores não tenham realizado análise de regressão dos teores de PB em função da idade de corte. Neumann et al. (2010), avaliando híbridos de sorgo com capimsudão em quatro idades de corte (variando de 40 a 145 dias após o plantio) observaram efeito quadrático nos teores de PB da planta inteira e dos colmos do híbrido BR 800, com ponto de mínimo aos 109,9 e 103,5 dias após o plantio, respectivamente e efeito linear decrescente no teor de PB das folhas, com 
redução diária de $0,08 \%$.

Avaliando um híbrido de sorgo com capimsudão manejado a uma altura média de 95,4 cm, Cunningham e Ragland (1971) obtiveram teor de proteína igual a $16,5 \%$, superior ao obtido nesse experimento. Já Tomich et al. (2003) avaliaram 25 híbridos de sorgo com capim-sudão e obtiveram, 57 dias após o plantio, teores de PB variando de 10,8 a $14,2 \%$ e um valor médio de $12,3 \%$, valores próximos aos observados nesse trabalho. De acordo com os autores esses teores de PB estão acima dos frequentemente observados para outros recursos forrageiros utilizados como alternativas às pastagens. Isso ressalta o potencial dos híbridos de sorgo com capim-sudão como alternativa para produção de forragem durante os períodos de queda na oferta e na qualidade das pastagens.

O híbrido mutante bmr-6 apresentou aproximadamente $21 \%$ a mais de $\mathrm{PB}$ em relação ao seu par isogênico normal. Essa resposta nem sempre é observada nos experimentos que comparam plantas isogênicas normais e mutantes $b m r$. Wedig, Jaster e Moore (1988), avaliando dois pares isogênicos de híbridos de sorgo com capim-sudão normais e mutantes $b m r$, obtiveram um amento de $13,4 \%$ no teor de proteína bruta em um dos híbridos mutantes em relação ao seu par normal, sendo que no outro par não foram observadas diferenças nessa variável. De acordo com esses autores os aumentos nos teores de PB não devem ser creditados ao efeito direto da mutação $b m r$, mas sim às diferenças de acúmulo de MS entre as linhagens isogênicas.

A interação entre híbrido e idade de corte foi significativa $(\mathrm{P}<0,05)$ para o teor de FDN (Tabela 4). O híbrido 156x2784 não apresentou efeito linear ou quadrático significativo, enquanto os híbridos BR 800, BRS 810 ( $b m r)$ e BRS 802 apresentaram efeito quadrático com pontos de máximo aos 62,0; 61,7 e 60,4 dias após o plantio, respectivamente. Nas idades de 52 e 67 dias o híbrido BRS 810 ( bmr) apresentou menor teor de FDN em relação aos demais híbridos $(\mathrm{P}<0,05)$, que não diferiram entre si $(\mathrm{P}>0,05)$, enquanto nas demais idades não foram observadas diferenças entre os híbridos $(\mathrm{P}>0,05)$. Tomich et al. (2003) avaliaram 25 híbridos de sorgo com capimsudão e obtiveram, 57 dias após o plantio, teores de FDN variando de 65,1 a $70,5 \%$ e um valor médio de 67,7\%, enquanto Mello et al. (2003) obtiveram, em um híbrido de sorgo com capim-sudão 50 e 85 dias após o plantio, teores de FDN nas folhas igual a 70,9 e $74,3 \%$ e nos colmos igual a 66,9 e $69,6 \%$, respectivamente. Neumann et al. (2010), avaliando híbridos de sorgo com capim-sudão em quatro idades de corte (variando de 40 a 145 dias após o plantio) observaram efeito quadrático nos teores de FDN do híbrido AG2501C, com ponto de máximo aos $80(79,5 \%$ de FDN) dias após o plantio.

Tabela 4. Teor de fibra em detergente neutro (FDN) em porcentagem da MS, coeficiente de variação (CV) e equações de regressão com seus respectivos coeficientes de determinação $\left(\mathrm{R}^{2}\right)$ e nível de significância $(\mathrm{P})$ de quatro híbridos de sorgo com capim-sudão em quatro idades de corte.

\begin{tabular}{cccccc}
\hline \multicolumn{5}{c}{ Idade ao Corte (dias) } \\
\hline Híbrido & 52 & 61 & 67 & 74 & Equação de Regressão \\
\hline BR 800 & $67,9^{\mathrm{A}}$ & $69,3^{\mathrm{A}}$ & $69,3^{\mathrm{A}}$ & $66,0^{\mathrm{A}}$ & $\mathrm{Y}=-\begin{array}{c}\text { (10,205+2,604 D - 0,021 D } \\
\left(\mathrm{R}^{2}: 95,7 ; \mathrm{P}<0,01\right)\end{array}$ \\
& & & & & $\mathrm{Y}=-40,482+3,453 \mathrm{D}-0,028 \mathrm{D}^{2}$ \\
BRS 810 (bmr) & $64,2^{\mathrm{B}}$ & $67,5^{\mathrm{A}}$ & $66,4^{\mathrm{B}}$ & $63,6^{\mathrm{A}}$ & $\left(\mathrm{R}^{2}: 98,4 ; \mathrm{P}<0,01\right)$ \\
BRS 802 & $69,0^{\mathrm{A}}$ & $70,7^{\mathrm{A}}$ & $70,3^{\mathrm{A}}$ & $63,6^{\mathrm{A}}$ & $\mathrm{Y}=-70,257+4,712 \mathrm{D}-0,039 \mathrm{D}^{2}$ \\
$156 \times 2784$ & $69,3^{\mathrm{A}}$ & $67,9^{\mathrm{A}}$ & $70,3^{\mathrm{A}}$ & $63,8^{\mathrm{A}}$ & $\left(\mathrm{R}^{2}: 96,5 ; \mathrm{P}<0,01\right)$ \\
\hline
\end{tabular}

Médias seguidas por letras distintas nas colunas diferem pelo teste $\mathrm{SNK}(\mathrm{P}<0,05), \mathrm{CV}=2,57 \%$.

$\mathrm{D}=$ dias após o plantio, variando de 52 a 74 dias, $\mathrm{NS}=$ não significativo.

Fonte: Elaboração dos autores. 
A importância da determinação das frações fibrosas das plantas forrageiras é decorrente da influência destes componentes sobre o consumo, digestibilidade, taxa de passagem e atividade mastigatória dos animais ruminantes. Se a dieta for muito rica em fibra sua densidade energética tende a ser baixa, seu consumo é limitado pelo enchimento ruminal e o desempenho animal pode ser comprometido. Em contrapartida, se as dietas apresentarem um baixo conteúdo de fibra, aumentase a incidência de distúrbios alimentares como a acidose, o que poderá levar a um comprometimento do desempenho e da saúde animal (MERTENS, 1997).

Amutação $b m r-6$ provocou reduções de 7,0 e 5,5\% no teor de FDN aos 52 e 67 dias, respectivamente. Beck et al. (2007) obtiveram reduções variando de 2 a $10 \%$, dependendo da idade de corte e dos híbridos avaliados, nos teores de FDN de híbridos de sorgo com capim-sudão mutantes $b m r$ em comparação a seus pares isogênicos convencionais. Casler, Pedersen e Undersander (2003) reportaram redução de 3,7\% no teor de FDN do capim-sudão mutante $b m r$ em relação ao normal e Cherney, Patterson e Johnson (1990) observaram redução de 2,7\% no teor de FDN do milheto mutante $b m r$ em relação ao normal, enquanto, enquanto Wedig et al. (1987) não encontraram diferenças nos teores de FDN ao avaliarem dois pares isogênicos de híbridos de sorgo com capim-sudão mutantes $b m r$ e normais.

O teor de FDA representa a composição da forrageira em celulose, lignina, nitrogênio insolúvel em detergente ácido, cinzas insolúveis em ácido e sílica e está mais relacionado ao potencial de digestibilidade de um determinado volumoso, enquanto o teor de FDN está mais relacionado ao seu consumo (VAN SOEST, 1994). A interação entre híbrido e idade de corte foi significativa $(\mathrm{P}<0,05)$ para essa variável (Tabela 5), sendo que os híbridos BRS 810 (bmr), BRS 802 apresentaram efeito linear decrescente e os híbridos BR 800 e 156x2784 não apresentaram efeito linear ou quadrático significativo. Aos 52 dias os híbridos BRS 802 e 156x2784 apresentaram valores semelhantes entre si $(\mathrm{P}>0,05)$ e superiores aos demais híbridos $(\mathrm{P}<0,05)$, que também não diferiram entre si $(\mathrm{P}>0,05)$. Aos 61 dias após o plantio o híbrido BRS 802 apresentou maior teor de FDA em relação aos demais híbridos $(\mathrm{P}<0,05)$, que não diferiram entre si $(\mathrm{P}>0,05)$. Aos 67 dias o híbrido BRS 810 (bmr) apresentou menor teor de FDA em relação aos demais híbridos $(\mathrm{P}<0,05)$, que não diferiram entre si $(\mathrm{P}>0,05)$, enquanto na última idade de corte, 74 dias após o plantio, não foram observadas diferenças nos teores de FDA dos diferentes híbridos avaliados $(\mathrm{P}>0,05)$.

Tabela 5. Teor de fibra em detergente ácido (FDA) em porcentagem da MS, coeficiente de variação (CV) e equações de regressão com seus respectivos coeficientes de determinação $\left(\mathrm{R}^{2}\right)$ e nível de significância $(\mathrm{P})$ de quatro híbridos de sorgo com capim-sudão em quatro idades de corte.

\begin{tabular}{cccccc}
\hline \multicolumn{5}{c}{ Idade ao Corte (dias) } \\
\hline Híbrido & 52 & 61 & 67 & 74 & Equação de Regressão \\
\hline BR 800 & $39,3^{\mathrm{B}}$ & $37,6^{\mathrm{B}}$ & $39,5^{\mathrm{A}}$ & $37,1^{\mathrm{A}}$ & $\mathrm{NS}$ \\
BRS 810 $(b m r)$ & $40,2^{\mathrm{B}}$ & $36,0^{\mathrm{B}}$ & $36,9^{\mathrm{B}}$ & $35,3^{\mathrm{A}}$ & $\mathrm{Y}=49,938-0,202 \mathrm{D}^{\mathrm{A}}\left(\mathrm{R}^{2}: 75,7 ; \mathrm{P}<0,01\right)$ \\
BRS 802 & $44,4^{\mathrm{A}}$ & $41,1^{\mathrm{A}}$ & $41,5^{\mathrm{A}}$ & $36,3^{\mathrm{A}}$ & $\left.\mathrm{Y}=61,817-0,331 \mathrm{D}^{\mathrm{R}}: 85,7 ; \mathrm{P}<0,01\right)$ \\
$156 \times 2784$ & $43,9^{\mathrm{A}}$ & $38,5^{\mathrm{B}}$ & $42,4^{\mathrm{A}}$ & $36,8^{\mathrm{A}}$ & NS \\
\hline
\end{tabular}

Médias seguidas por letras distintas nas colunas diferem pelo teste $\mathrm{SNK}(\mathrm{P}<0,05), \mathrm{CV}=4,55 \%$.

$\mathrm{D}=$ dias após o plantio, variando de 52 a 74 dias, $\mathrm{NS}=$ não significativo.

Fonte: Elaboração dos autores. 
Tomich et al. (2003) avaliaram 25 híbridos de sorgo com capim-sudão e obtiveram, 57 dias após o plantio, teores de FDA variando de 37,4 a 41,9\% e um valor médio de 39,8\%, valores próximos observados nesse experimento, enquanto Mello et al. (2003) obtiveram, em um híbrido de sorgo com capim-sudão 50 e 85 dias após o plantio, teores de FDA nas folhas igual a 37,7 e $38,5 \%$ e nos colmos igual a 39,7 e $41,1 \%$, respectivamente.

Experimentos que avaliaram os teores de FDA de híbridos de sorgo com capim-sudão ao longo de várias idades de corte não são muito frequentes na literatura e apresentam resultados conflitantes. Ademosum, Baumgardt e Scholl (1968), avaliando um híbrido de sorgo de corte e pastejo em 12 idades de corte (variando de 52 a 85 dias após o plantio) observaram que o teor de FDA aumentou ao longo dos cortes, variando de 29,9 a 37,8\%, já Beck et al. (2007) observaram valores de FDA igual a 35,$5 ; 41,4 ; 42,4 ; 43,4$ e $43,2 \%$ quando um híbrido de sorgo com capim-sudão foi submetido ao corte aos 34, 41, 48, 55 e 63 dias após o plantio, respectivamente, embora esses autores não tenham realizado análise de regressão dos teores de FDA em função da idade de corte. Neumann et al. (2010), avaliando quatro híbridos de sorgo com capimsudão em quatro idades de corte (variando de 40 a 145 dias após o plantio) observaram que os teores de FDA apresentaram efeito quadrático, com ponto de máximo aos 74 dias após o plantio.

A mutação bmr-6 provocou reduções de 9,5; 12,4 e $11,1 \%$ nos teores de FDA da planta inteira nas idades de 52, 61 e 67 dias, respectivamente, ao passo que na idade de 74 dias não foram observadas diferenças entre os híbridos que compõem o par isogênico normal e mutante $b m r$. Beck et al. (2007) obtiveram reduções variando de 4 a $10 \%$, dependendo da idade de corte e dos híbridos avaliados, nos teores de FDA de híbridos de sorgo com capimsudão mutantes $b m r$, enquanto Fritz, Moore e Jaster (1988) observaram que a presença da mutação $b m r$ levou a uma redução de 8 a 10\% no teor de FDA. Trabalhando com capim-sudão normal e mutante $b m r$, Ledgerwood et al. (2009) observaram redução de $4,9 \%$ no teor de FDA do capim-sudão mutante bmr em relação ao normal, enquanto Gerhardt et al. (1994) observaram redução de 15,2\%. Wedig et al. (1987) e Wedig, Jaster e Moore (1988), ao avaliarem as silagens e os fenos produzidos com dois híbridos de sorgo com capim-sudão convencionais e seus pares isogênicos portadores de nervura marrom, não observaram redução nos teores de FDA em função da mutação $b m r$. As variações observadas nos efeitos das mutações $b m r$ entre experimentos corroboram com a colocação de Cherney et al. (1991) de que a expressão das mutações $b m r$ são frequentemente modificadas pelo ambiente e pela linhagem de células em que ela é expressada, e justifica a importância de se testar os efeitos desses genes em ambientes e linhagens diversos.

O processo de lignificação é reconhecido como o principal fator que leva à redução da digestibilidade da parede celular vegetal (VAN SOEST, 1994), portanto uma alteração no conteúdo de lignina pode interferir diretamente com a digestibilidade in vitro da MS e da FDN. A interação entre híbrido e idade de corte não foi significativa para o teor de lignina $(\mathrm{P}>0,05)$ (Tabela 6) e não foram observados efeito linear ou quadrático significativos para essa variável. 
Tabela 6. Teor de lignina em porcentagem da MS, coeficiente de variação (CV) e equações de regressão com seus respectivos coeficientes de determinação $\left(\mathrm{R}^{2}\right)$ e nível de significância $(\mathrm{P})$ de quatro híbridos de sorgo com capimsudão em quatro idades de corte.

\begin{tabular}{ccccccc}
\hline \multicolumn{7}{c}{ Idade ao Corte (dias) } \\
\hline Híbrido & 52 & 61 & 67 & 74 & Média & Equação de Regressão \\
\hline BR 800 & 3,32 & 2,99 & 4,39 & 4,04 & $3,69^{\mathrm{B}}$ & \\
BRS 810 $(\mathrm{bmr})$ & 2,62 & 2,33 & 2,55 & 2,47 & $2,49^{\mathrm{C}}$ & NS \\
BRS 802 & 4,68 & 4,26 & 4,61 & 4,14 & $4,42^{\mathrm{A}}$ & \\
156x2784 & 4,22 & 3,47 & 4,75 & 4,21 & $4,16^{\mathrm{A}}$ & \\
\hline
\end{tabular}

Médias seguidas por letras distintas nas colunas diferem pelo teste $\mathrm{SNK}(\mathrm{P}<0,05), \mathrm{CV}=12,68 \%$.

$\mathrm{NS}$ = não significativo.

Fonte: Elaboração dos autores.

Independente da idade de corte, os híbridos BRS 802 e 156×2784 apresentaram teores de lignina semelhantes entre si $(\mathrm{P}>0,05)$ e superiores ao híbrido BR $800(\mathrm{P}<0,05)$, que foi superior ao híbrido BRS 810 (bmr $)(\mathrm{P}<0,05)$. Tomich et al. (2003) avaliaram 25 híbridos de sorgo com capim-sudão e obtiveram, 57 dias após o plantio, teores de lignina na planta inteira variando de 3,8 a $6,5 \%$ e um valor médio de $5,1 \%$, enquanto Mello et al. (2003) obtiveram, em um híbrido de sorgo com capim-sudão cortado $50 \mathrm{e}$ 85 dias após o plantio, teores de lignina nas folhas igual a 4,5 e 6,0\% e nos colmos igual a 6,6 e 5,8\%, respectivamente. Ademosum, Baumgardt e Scholl (1968), avaliando um híbrido de sorgo de corte e pastejo em 12 idades de corte (variando de 52 a 85 dias após o plantio) observaram que o teor de lignina aumentou ao longo dos cortes, variando de 2,6 a $4,6 \%$ no primeiro e último corte, respectivamente. São poucos os trabalhos que avaliaram o teor de lignina em híbridos de sorgo com capim-sudão ao longo de várias idades de corte. Estudos realizados com outras gramíneas tropicais relacionam o aumento na idade de corte com elevações nos teores de lignina e queda no valor nutritivo, o que não foi observado nesse experimento. Isso indica que novas pesquisas são necessárias a fim de determinar-se o melhor momento de colheita dessa forrageira.

A mutação $b m r-6$ provocou uma redução média de $43,7 \%$ no teor de lignina. Oba e Allen (2000) obtiveram redução de $35 \%$ nos teores de lignina e maiores digestibilidades in vitro da MS (78,2\% $\mathrm{x}$ $83,3 \%$ ) e da FDN (46,5\% x 55,9\%) no milho mutante $\mathrm{bm}_{3}$ em relação ao seu par isogênico normal. Ebling e Kung Júnior (2004) compararam o valor nutritivo das silagens de milho normal e mutante $b m r$ e não foram observadas diferenças nos teores de FDN e FDA, porém o material mutante apresentou uma redução de $65 \%$ no teor de lignina em comparação ao híbrido normal. Essa menor concentração de lignina proporcionou uma maior degradação in situ da FDN, que foi de 54\% para o híbrido mutante e de $39 \%$ para o híbrido normal. Wedig et al. (1987) ao avaliarem as silagens produzidas com dois pares de híbridos de sorgo com capim-sudão convencionais e seus pares isogênicos portadores de nervura marrom, observaram reduções de 33,3 e 27,0\% nos teores de lignina em cada um dos híbridos mutantes em relação aos seus pares normais. Quando forneceram para novilhas as silagens dos dois pares isogênicos, em apenas um deles foram observados maiores coeficientes de digestibilidade aparente da matéria orgânica (54,6\% x 64,2\%), FDN (55,7\% x 65,6\%), FDA $(54,1 \% \times 62,3)$, celulose $(63,4 \% \times 71,1 \%)$ e hemiceluloses $(55,5 \%$ x 68,1\%) no híbrido mutante em relação ao seu par isogênico normal.

O comportamento variado nos teores das frações fibrosas (FDN, FDA e lignina) obtidos nesse e em outros experimentos, que influenciam diretamente a digestibilidade e o valor nutritivo dessa forrageira, pode ser resultado de alterações na distribuição do 
crescimento e da composição estrutural da planta, inclusive alterações induzidas pela entrada na fase reprodutiva e pela produção de sementes. Isso indica que mais pesquisas são necessárias para a avaliação de híbridos e cultivares comerciais de sorgo de corte e pastejo com objetivo de determinar o melhor momento de utilização desse recurso forrageiro.

A interação entre híbrido e idade de corte foi significativa $(\mathrm{P}<0,05)$ para a DIVMS (Tabela 7), sendo que os híbridos BR 800 e BRS 802 apresentaram efeito quadrático com pontos de mínimo em 65,5 e 62,8 dias após o plantio, respectivamente, e os híbridos BRS 810 (bmr) e 156x2784 não apresentaram efeito linear ou quadrático significativo. 52 dias após o plantio os híbridos BRS 802 e 156×2784 apresentaram valores de DIVMS semelhantes entre si $(\mathrm{P}>0,05)$ e inferiores ao híbrido BR $800(\mathrm{P}<0,05)$, que também foi inferior ao híbrido BRS $810(b m r)(\mathrm{P}<0,05) .61$ dias após o plantio o híbrido BRS 802 apresentou valor inferior aos demais híbridos $(\mathrm{P}<0,05)$, que não diferiram entre si $(\mathrm{P}>0,05) .67$ dias após o plantio o híbrido BRS 810 ( $b m r)$ apresentou valor superior aos híbridos BRS 802 e 156x2784 ( $<<0,05)$, que não diferiram entre si $(\mathrm{P}>0,05)$, enquanto o híbrido $\mathrm{BR}$ 800 apresentou valor intermediário mas semelhante aos demais $(\mathrm{P}>0,05) .74$ dias após o plantio o híbrido BRS $810(\mathrm{bmr})$ apresentou maior DIVMS em relação aos demais híbridos $(\mathrm{P}<0,05)$, que não diferiram entre si $(\mathrm{P}>0,05)$.

Tabela 7. Digestibilidade in vitro da matéria seca (DIVMS) em porcentagem da MS, coeficiente de variação (CV) e equações de regressão com seus respectivos coeficientes de determinação $\left(\mathrm{R}^{2}\right)$ e nível de significância $(\mathrm{P})$ de quatro híbridos de sorgo com capim-sudão em quatro idades de corte.

\begin{tabular}{cccccc}
\hline \multicolumn{5}{c}{ Idade ao Corte (dias) } \\
\hline Híbrido & 52 & 61 & 67 & 74 & Equação de Regressão \\
\hline BR 800 & $58,1^{\mathrm{B}}$ & $53,5^{\mathrm{A}}$ & $53,6^{\mathrm{AB}}$ & $54,9^{\mathrm{B}}$ & $\mathrm{Y}=165,038-3,406 \mathrm{D}+0,026 \mathrm{D}^{2}$ \\
BRS 810 (bmr) & $61,3^{\mathrm{A}}$ & $52,0^{\mathrm{A}}$ & $55,7^{\mathrm{A}}$ & $57,5^{\mathrm{A}}$ & $\left(\mathrm{R}^{2}: 98,9 ; \mathrm{P}<0,01\right)$ \\
BRS 802 & $53,2^{\mathrm{C}}$ & $49,2^{\mathrm{B}}$ & $50,7^{\mathrm{B}}$ & $54,7^{\mathrm{B}}$ & $\mathrm{Y}=193,409-4,646 \mathrm{D}+0,037 \mathrm{D}^{2}$ \\
$156 \times 2784$ & $53,1^{\mathrm{C}}$ & $53,2^{\mathrm{A}}$ & $50,6^{\mathrm{B}}$ & $54,0^{\mathrm{B}}$ & $\left(\mathrm{R}^{2}: 98,8 ; \mathrm{P}<0,01\right)$ \\
\hline
\end{tabular}

Médias seguidas por letras distintas nas colunas diferem pelo teste $\mathrm{SNK}(\mathrm{P}<0,05), \mathrm{CV}=3,38 \%$.

$\mathrm{D}=$ dias após o plantio, variando de 52 a 74 dias, $\mathrm{NS}=$ não significativo.

Fonte: Elaboração dos autores.

Tomich (2003) avaliou doze híbridos de sorgo com capim-sudão em três cortes sucessivos (44 dias após o plantio, 30 e 31 dias de rebrota) e observou valores médios de DIVMS da planta inteira de 66,2; 67,2 e $65,6 \%$, respectivamente para o primeiro, segundo e terceiro corte. Os resultados obtidos por este autor estão acima dos encontrados no presente trabalho, provavelmente em função dos diferentes estádios vegetativos.

A DIVMS apresentou correlação negativa com os teores de FDN ( $r=-0,60 ; \mathrm{P}<0,001)$, FDA ( $\mathrm{r}=$
$-0,35 ; \mathrm{P}<0,001)$ e lignina $(\mathrm{r}=-0,43 ; \mathrm{P}<0,001)$. Plantas forrageiras frequentemente apresentam altos teores de carboidratos estruturais e baixa digestibilidade, o que limita a disponibilidade de energia e o consumo de matéria seca por animais que recebem dietas ricas em volumosos (JUNG; ALLEN, 1995). Em função disso, existe um grande esforço entre melhoristas de plantas e nutricionistas de ruminantes no sentido de desenvolver cultivares de forrageiras que apresentem altos valores de digestibilidade, destacando-se a introdução das mutações $b m r$, que geralmente conferem maiores 
digestibilidade da MS e das frações fibrosas. Nesse experimento, a mutação bmr-6 provocou aumentos de 15,$2 ; 5,7 ; 9,9$ e 5,5\% nas DIVMS da planta inteira nas idades de 52, 61, 67 e 74 dias, respectivamente. Beck et al. (2007) observaram que a mutação bmr provocou aumento nas degradabilidades efetivas da MS, avaliadas in situ, em híbridos de sorgo com capim-sudão colhidos 34, 48 e 63 dias após o corte. Oba e Allen (2000) obtiveram aumento de 6,1\% na DIVMS no milho mutante $b m r$ em relação ao seu par isogênico normal. Esses resultados revelam o potencial da utilização das mutações $b m r$ como forma de aumentar a digestibilidade de híbridos de sorgo com capim-sudão.

A interação entre híbrido e idade de corte foi significativa $(\mathrm{P}<0,05)$ para a DIVFDN (Tabela
8), sendo que os híbridos BRS 810 (bmr) e BRS 802 não apresentaram efeito linear ou quadrático significativo e os híbridos BR 800 e 156×2784 apresentaram efeito linear decrescente, com reduções diárias de 0,48 e $0,34 \%$, respectivamente. Nas idades de 52 e 74 dias após o plantio o híbrido BR 800 apresentou DIVFDN inferior ao híbrido BRS $810(\mathrm{bmr})$ e superior aos híbridos BRS 802 e 156x2784 $(\mathrm{P}<0,05)$, que não diferiram entre si ( $\mathrm{P}>0,05)$. 61 dias após o plantio o híbrido BR 800 destacou-se por apresentar maior DIVMS em relação aos demais $(\mathrm{P}<0,05)$ e os híbridos BRS 810 (bmr) e $156 \times 2784$ apresentaram valores semelhantes entre si $(\mathrm{P}>0,05)$ e superiores ao BRS $802(\mathrm{P}<0,05) .67$ dias após o plantio o híbrido BRS 802 apresentou menor DIVFDN em relação aos demais híbridos $(\mathrm{P}<0,05)$, que não diferiram entre si $(\mathrm{P}>0,05)$.

Tabela 8. Digestibilidade in vitro da fibra em detergente neutro (DIVFDN) em porcentagem da FDN, coeficiente de variação $(\mathrm{CV})$ e equações de regressão com seus respectivos coeficientes de determinação $\left(\mathrm{R}^{2}\right)$ e nível de significância (P) de quatro híbridos de sorgo com capim-sudão em quatro idades de corte.

\begin{tabular}{cccccc}
\hline \multicolumn{5}{c}{ Idade ao Corte (dias) } \\
\hline Híbrido & 52 & 61 & 67 & 74 & Equação de Regressão \\
\hline BR 800 & $53,4^{\mathrm{B}}$ & $46,4^{\mathrm{A}}$ & $45,4^{\mathrm{A}}$ & $42,5^{\mathrm{B}}$ & $\mathrm{Y}=77,469-0,481 \mathrm{D}\left(\mathrm{R}^{2}: 93,3 ; \mathrm{P}<0,01\right)$ \\
BRS 810 $(b m r)$ & $56,8^{\mathrm{A}}$ & $43,5^{\mathrm{B}}$ & $47,4^{\mathrm{A}}$ & $46,3^{\mathrm{A}}$ & NS \\
BRS 802 & $47,3^{\mathrm{C}}$ & $39,8^{\mathrm{C}}$ & $41,3^{\mathrm{B}}$ & $38,7^{\mathrm{C}}$ & NS \\
$156 \times 2784$ & $46,2^{\mathrm{C}}$ & $43,6^{\mathrm{B}}$ & $41,4^{\mathrm{B}}$ & $38,7^{\mathrm{C}}$ & $\mathrm{Y}=64,154-0,342 \mathrm{D}\left(\mathrm{R}^{2}: 99,4 ; \mathrm{P}<0,01\right)$ \\
\hline
\end{tabular}

Médias seguidas por letras distintas nas colunas diferem pelo teste $\mathrm{SNK}(\mathrm{P}<0,05), \mathrm{CV}=5,07 \%$.

$\mathrm{D}=$ dias após o plantio, variando de 52 a 74 dias, NS = não significativo.

Fonte: Elaboração dos autores.

De acordo com Oba e Allen (1999a), a digestibilidade da FDN é um parâmetro muito importante na avaliação da qualidade das forragens. A fração fibrosa dos alimentos é fermentada lentamente e é retida no rúmen por mais tempo que as frações não fibrosas, causando o efeito de enchimento ruminal. Como esse efeito frequentemente limita o consumo de MS, um desaparecimento mais rápido da FDN, em função de uma maior taxa de degradação ou de passagem dessa fração, reduz o efeito de enchimento ruminal e possibilita um maior consumo voluntário. Além disso, uma fração fibrosa mais digestível aumenta a densidade energética da dieta e a produção de proteína microbiana. De acordo com dados publicados por esses autores em outro trabalho, um aumento na digestibilidade da FDN em uma unidade percentual resulta em um aumento potencial do consumo de matéria seca em $0,17 \mathrm{~kg} /$ dia e da produção de leite corrigido para 4\% de gordura em 0,25 kg/dia (OBA; ALLEN, 1999b).

A mutação $b m r-6$ provocou aumentos de 20,1; 9,$3 ; 14,8$ e $19,6 \%$ na DIVFDN nas idades de 52, 
61, 67 e 74 dias, respectivamente. Os aumentos na digestibilidade provocados pela mutação $b m r-6$ foram maiores na FDN do que na MS, o que está de acordo a informação de Van Soest (1994) de que a lignina exerce seu efeito inibitório apenas sobre a digestibilidade dos componentes da parede celular, e não do conteúdo celular. Nesse experimento a DIVFDN correlacionou-se negativamente com os teores de lignina $(\mathrm{r}=-0,40 ; \mathrm{P}<0,001)$.

Casler, Pedersen e Undersander (2003) avaliaram o valor nutritivo de dois cultivares de capim-sudão mutantes $b m r-6$ e de seus pares isogênicos normais em dois cortes sucessivos e observaram um aumento de $7,2 \%$ na DIVFDN dos cultivares mutantes, enquanto Oba e Allen (2000) obtiveram aumento de 20,2\% nesse parâmetro no milho mutante $\mathrm{bmr}$ em relação ao seu par isogênico normal. Ledgerwood et al. (2009) avaliaram a DIVFDN dos fenos de um par isogênico de capim-sudão normal e mutante bmr. Quando esse parâmetro foi avaliado nos tempos de incubação de 24, 48 e 72 horas a mutação bmr aumentou em até $8,8 \%$ os seus valores, o que não ocorreu no tempo de incubação de 12 horas, provavelmente em função de que a maior inibição da degradação pela lignina ocorre nas frações fibrosas, que são degradadas em maiores tempos de incubação. Quando esses autores forneceram esses fenos para ovelhas em um ensaio de digestibilidade aparente, a mutação bmr provocou aumentos de 4,1 e $8,3 \%$ nas digestibilidades aparentes da matéria orgânica e da FDN, respectivamente. Beck et al. (2007) observaram que a mutação bmr provocou aumentos nas degradabilidades efetivas da MS, avaliadas in situ, em híbridos de sorgo com capim-sudão colhidos em três idades de corte. Esses aumentos foram de 5,8; 12,5 e 21,7\%, respectivamente para as idades de corte de 34,48 e 63 dias, mostrando que, nesse caso, o efeito da mutação $b m r$ foi maior em idades mais avançadas, provavelmente em função da maior lignificação das frações fibrosas nessas idades.

A decisão do ponto de colheita deve ser realizada associando o valor nutritivo às características produtivas e à categoria animal que será utilizada, pois em todas as idades de corte o valor nutricional dos híbridos de sorgo com capim-sudão pode ser considerado satisfatório. Também constatou-se de maneira geral que a mutação $b m r-6$ provocou aumento do valor nutritivo em função da redução dos teores de FDN, FDA e lignina e aumento do teor de PB e da DIVMS e DIVFDN. Mais estudos devem ser realizados na comparação de híbridos isogênicos para definição do benefício da mutação bmr na cultura do sorgo.

\section{Conclusões}

O híbrido BRS 810 (bmr) destacou-se em relação aos demais híbridos por apresentar menor teor de lignina, independente da idade de corte.

O híbrido BR 800 destacou-se em relação aos demais híbridos convencionais por apresentar menores teores de FDA e lignina e maior DIVFDN.

O híbrido BR 800 apresentou, aos 61 e 67 dias após o plantio, DIVMS e DIVFDN semelhantes ou até superiores às do híbrido BRS $810(\mathrm{bmr})$, indicando que a seleção de materiais mais digestíveis é possível por outros meios além das mutações $b m r$.

\section{Agradecimentos}

Ao Conselho Nacional de Desenvolvimento Científico e Tecnológico - CNPq, Coordenação de Aperfeiçoamento de Pessoal de Nível Superior CAPES, Embrapa Milho e Sorgo e Departamento de Zootecnia da Escola de Veterinária da Universidade Federal de Minas Gerais.

\section{Referências}

ADEMOSUM, A. A.; BAUMGARDT, B. R.; SCHOLL, J. M. Evaluation of a sorghum-sudangrass hybrid at varying stages of maturity on the basis of intake, digestibility and chemical composition. Journal of Animal Science, Champaign, v. 27, n. 3, p. 818-823, 1968. 
ASSOCIATION OF OFFICIAL ANALYTICAL CHEMISTS - AOAC. Official methods of analysis. 16. ed. Washington: AOAC, 1995. 2000 p.

ASTIGARRAGA, L.; BIANCO, A.; MELLO, R.; MONTEDÓNICO, D. Comparison of brown midrib sorghum with conventional sorghum forage for grazing dairy cows. American Journal of Plant Science, Newark, v. 5, n. 7, p. 955-962, 2014.

BECK, P. A.; HUTCHINSON, S.; GUNTER, S. A.; LOSI, T. C.; STEWART, C. B.; CAPPS, P. K.; PHILLIPS, J. M. Chemical composition and in situ dry matter and fiber disappearance of sorghum x sudangrass hybrids. Journal of Animal Science, Champaign, v. 85, n. 2, p. 545-555, 2007.

CASLER, M. D.; PEDERSEN, J. F.; UNDERSANDER, D. J. Forage yield and economic losses associated with the brown-midrib trait in sudangrass. Crop Science, Madison, v. 43, n. 3, p. 782-789, 2003.

CHERNEY, D. J.; PATTERSON, A. J.; JOHNSON, K. D. Digestibility and feeding value of pearl millet as influenced by the brown-midrib, low-lignin trait. Journal of Animal Science, Champaign, v. 68, n. 12, p. 43454351, 1990.

CHERNEY, J. H.; CHERNEY, D. J. R.; AKIN, D. E.; AXTELL, J. D. Potential of brown-midrib, low-lignin mutants for improving forage quality. Advances in Agronomy, v. 46, p. 157-198, 1991.

CUNNINGHAM, M. D.; RAGLAND, W. W. Plant composition and feeding value of sudangrass and sorghum-sudangrass in a controlled grazing system. Journal of Dairy Science, Madison, v. 54, n. 10, p. 14611464, 1971.

EBLING, T. L.; KUNG JUNIOR, L. A comparison of processed conventional corn silage to unprocessed and processed brown midrib corn silage on intake, digestion, and milk production by dairy cows. Journal of Dairy Science, Madison, v. 87, n. 8, p. 2519-2526, 2004.

FRITZ, J. O.; MOORE, K. J.; JASTER, E. H. In situ digestion kinetics and ruminal turnover rates of normal and brown midrib mutant sorghum $\mathrm{x}$ sudangrass hays fed to nonlactating Holstein cows. Journal of Dairy Science, Madison, v. 71, n. 12, p. 3345-3351, 1988.

GERHARDT, R. L.; FRITZ, J. O.; MOORE, K. J.; JASTER, E. H. Digestion kinetics and composition of normal and brown midrib sorghum morphological components. Crop Science, Madison, v. 34, n. 5, p. 203223, 1994.

HOLDEN, L. A. Comparison of methods of in vitro dry matter digestibility for ten feeds. Journal of Animal Science, Champaign, v. 68, n. 11, p. 3832-3842, 1999.
JAYME, D. G.; PIRES, D. A. A.; GUIMARÃES JÚNIOR, R.; GONÇALVES, L. C.; RODRIGUES, J. A. S.; RODRIGUEZ, N. M.; BORGES, A. L. C. C.; BORGES, I.; SALIBA, E. O. S.; JAYME, C. G. Composição bromatológica e perfil de fermentação das silagens de cinco híbridos de capim-sudão (Sorghum bicolor x Sorghum sudanense). Revista Brasileira de Milho e Sorgo, Sete Lagoas, v. 6, n. 3, p. 351-363, 2007.

JUNG, H. G.; ALLEN M. S. Characteristics of plant cell walls affecting intake and digestibility of forages by ruminants. Journal of Animal Science, Champaign, v. 73, n. 9, p. 2774-2790, 1995.

LEDGERWOOD, D. N.; DEPETERS, E. J.; ROBINSON, P. H.; TAYLOR, S. J.; HEGUY, J. M. Assessment of a brown midrib $(B M R)$ mutant gene on the nutritive value of sudangrass using in vitro and in vivo techniques. Animal Feed Science and Technology, Amsterdam, v. 150, n. 3-4, p. 207-222, 2009.

McDONALD, P. J.; HENDERSON, A. R.; HERON, S. J. E. The biochemistry of silage. 2. ed. Mallow: Chalcombe Publications, 1991. 340 p.

MELLO, R.; NORNBERG, J. L.; ROCHA, M. G.; DAVID, D. B. Análise produtiva e qualitativa de um híbrido de sorgo interespecífico submetido a dois cortes. Revista Brasileira de Milho e Sorgo, Sete Lagoas, v. 2, n. 1, p. 20-33, 2003.

MERTENS, D. R. Creating a system for meeting the fiber requirements of dairy cows. Journal of Dairy Science, Madison, v. 80, n. 7, p. 1463-1481, 1997.

NATIONAL RESEARCH COUNCIL - NRC. Nutrient requirements of dairy cattle. Washington, D. C.: National Academy of Science, National Academy Press, 1989. $157 \mathrm{p}$.

NEUMANN, M.; RESTLE, J.; SOUZA, A. N. M.; PELLEGRINI, L. G.; ZANETTE, P. M.; NORNBERG, J. L.; SANDINI, I. E. Desempenho vegetativo e qualitativo do sorgo forrageiro (Sorghum bicolor $x$ Sorghum sudanense) em manejo de cortes. Revista Brasileira de Milho e Sorgo, Sete Lagoas, v. 9, n. 3, p. 10-15, 2010.

OBA, M.; ALLEN, M. S. Effects of brown midrib 3 mutation in corn silage on dry matter intake and productivity of high yielding dairy cows. Journal of Dairy Science, Madison, v. 82, n. 1, p. 135-142, 1999a.

Effects of brown midrib 3 mutation in corn silage on productivity of dairy cows fed two concentrations of dietary neutral detergent fiber: 1 . Feeding behavior and nutrient utilization. Journal of Dairy Science, Madison, v. 83, n. 6, p. 1333-1341, 2000. 
Evaluation of the importance of digestibility of NDF from forage: effects on dry matter intake and milk yield of dairy cows. Journal of Dairy Science, Madison, v. 82, n. 3, p. 589-596, 1999 b.

RIBAS, M. N. Avaliação agronômica e nutricional de híbridos de sorgo com capim-sudão, normais e mutantes BMR - portadores de nervura marrom. 2010. Tese (Doutorado em Zootecnia) - Escola de Veterinária da Universidade Federal de Minas Gerias, Belo Horizonte.

ROBERTSON, J. B.; VAN SOEST, P. J. The detergent system of analysis and its application to humans foods. In: JAMES, H. P. T.; THEANDER, O. (Ed.). The analysis of dietary fiber in food. New York: Marcel Dekker, 1981. p. 123-158.

TILLEY, J. M. A.; TERRY, R. A. A two stage technique for the in vitro digestion of forage crops. Journal of the British Grassland Society, Oxford, v. 18, n. 1, p. 104112, 1963.

TOMICH, T. R. Potencial forrageiro de híbridos de sorgo com capim sudão avaliados em regime de cortes. 2003. Tese (Doutorado em Ciência Animal) - Escola de Veterinária da Universidade Federal de Minas Gerias, Belo Horizonte.
TOMICH, T. R.; GONÇALVES, L. C.; MAURÍCIO, R. M.; PEREIRA, L. G. R.; RODRIGUES, J. A. S. Composição química e cinética de fermentação ruminal de híbridos de sorgo com capim-sudão. Arquivo Brasileiro de Medicina Veterinária e Zootecnia, Belo Horizonte, v. 55, n. 6, p. 747-755, 2003.

VAN SOEST, P. J. Nutritional ecology of the ruminant. 2. ed. Ithaca: Cornell University Press, 1994. 476 p.

WEDIG, C. L.; JASTER, E. H.; MOORE, K. J. Effect of brown midrib and normal genotype of sorghum $\mathrm{x}$ sudangrass on ruminal fluid and particulate rate of passage from the rumen and extent of digestion at various sites along the gastrointestinal tract in sheep. Journal of Animal Science, Champaign, v. 66, n. 2, p. 559-565, 1988.

WEDIG, C. L.; JASTER, E. H.; MOORE, K. J.; MERCHEN, N. R. Rumen turnover and digestion of normal and brown midrib sorghum sudangrass hybrid silages in dairy cattle. Journal of Dairy Science, Madison, v. 70 , n. 6 , p. 1220-1227, 1987.

WORKER JUNIOR, G. F. Sudangrass and sudangrass hybrids responses to row spacing and plant maturity on yield and chemical composition. Agronomy Journal, Madison, v. 65, n. 6, p. 975-977, 1973. 